\title{
Afzelia quanzensis bark extract for green synthesis of silver nanoparticles and study of their antibacterial activity
}

\author{
$\operatorname{Mambo}^{\text {Moyo }}{ }^{1}$ ( $)$ Makore Gomba $^{1} \cdot$ Tichaona Nharingo $^{1}$
}

Received: 14 September 2014/ Accepted: 10 September 2015/Published online: 24 September 2015

(C) The Author(s) 2015. This article is published with open access at Springerlink.com

\begin{abstract}
In the present study, Afzelia quanzensis bark extract was tested for the biosynthesis of silver nanoparticles (AgNPs). Based on UV-Vis spectrum analysis, the characteristic absorption band was observed at $427 \mathrm{~nm}$. Furthermore, the size and shape of the nanoparticles ranged from 10 to $80 \mathrm{~nm}$ and were spherical in shape as observed through SEM analysis. In addition, the X-ray diffraction analysis showed that the silver nanoparticles are crystalline in nature and have a face-centred cubic structure. Based on FTIR analysis, the presence of phytochemical functional groups such as carboxyl $(-\mathrm{C}=\mathrm{O})$ and amine $(\mathrm{N}-\mathrm{H})$ in Afzelia quanzensis bark extract further confirmed the responsible reducing agents for nanoparticles formation. Interestingly, the synthesized silver nanoparticles at $50 \mathrm{mg} /$ L concentration showed significant antibacterial activity against Escherichia coli and Staphylococcus aureus.
\end{abstract}

Keywords Biological synthesis - Silver nanoparticles · Bark extract · Antibacterial activity

\section{Introduction}

At present, nanotechnology is a rapidly developing field of importance since it deals with the synthesis and stabilization of different metal nanoparticles. Among the particles, silver nanoparticles (AgNPs) have become the focus of intensive research due to several important applications

Mambo Moyo

moyom@msu.ac.zw

1 Department of Chemical Technology, Faculty of Science, Midlands State University, P. Bag 9055, Senga, Gweru, Zimbabwe such as their use in bio-labelling, sensors, drug delivery system, antimicrobial agents and filters [1,2]. The synthesized silver nanoparticles exhibit new or improved properties depending upon their size, morphology and distribution [3]. The production of pure and well-defined metal-based nanoparticles by chemical reduction [4], thermal treatment, irradiation [5] and laser ablation [6] have been reported. On one hand, organic solvents, toxic reducing agents, high-pressure and high-temperature conversion which are potentially dangerous to the environment are used [7]. Hence, a pressing need to shift from physical and chemical synthesis to 'green' chemistry and bioprocesses is of major interest.

In the last decade, the biosynthesis of nanoparticles has received increasing attention due to the growing need to develop environmentally benign technologies in material synthesis $[8,9]$. Biological routes for the synthesis of metal nanoparticles by exploiting bacteria [10, 11], marine fungus Penicillium fellutanum [1], fungus Aspergillus foetidus [12], yeast [13, 14], enzymes [15] have been reported. However, one of the major drawbacks in using microbes for nanoparticle synthesis is the elaborate process of maintaining microbial cultures. The use of plant extracts for the synthesis of nanoparticles have gained momentum in recent years and could be advantageous over other environmentally benign biological processes by eliminating the elaborate process of maintaining cell cultures, being simply, eco-friendly and this could be an exciting possibility that is relatively unexplored and under exploited [16]. Green silver nanoparticles synthesis using various natural products like Magnolia kobus [17], Acacia leucophloea extract [18], Zizyphus xylopyrus bark extract [19], aloevera plant extract [20,21], Cinnamon zeylanicum bark extract [22], Curcuma longa tuber powder [23] and Jatropha curcas [9] have been reported. However, the 
potential of other plants as sources of biomaterial for the synthesis of new nanoparticles are yet to be entirely explored.

It has been reported that plants contain different phytochemical products [24] which are able to breakdown the silver nitrate, a complex hazardous chemical into $\mathrm{Ag}^{+}$and $\mathrm{NO}_{3}{ }^{-}$ions. In the process, the toxic $\mathrm{Ag}^{+}$ions are further reduced to the nontoxic $\left(\mathrm{Ag}^{0}\right)$ metallic nanoparticles through the use of different functional groups on the surface of the extract [25]. In the present study, we selected Afzelia quanzensis, Pod mahogany (English), Mujarakamba (Shona name in Zimbabwe) bark as a biomaterial for supplying the different phytochemicals required for the synthesis of silver nanoparticles and the mechanism involved in the synthesis is illustrated in Fig. 1. The plant is economic and abundantly available in Zimbabwe. It is a medium-sized to large deciduous tree and has a bark which is greyish-brown, flaking and leaving pale patches [26]. It produces fruits which consist of a large flattened pod, thickly woody, $10-17 \mathrm{~cm}$, and splitting to reveal large, shiny black seeds with a bright red aril. In medicine, roots are used to treat gonorrhoea, chest pains, kidney problems, bilharzia, eye problems and snakebites, and a small piece of bark is applied to an aching tooth. The plant can be categorized as:

Taxonomy

Kingdom: Plantae

Division: Tracheophyta

Subdivision: Spermatophytina

Class: Magnoliopsida

Order: Fabales

Family: Fabaceae

Genus: Afzelia Sm.-mahogany

Species: Afzelia quanzensis Welw._pod mahogany
In the present study, we used plant bark extracts for synthesis of silver nanoparticles by monitoring their conversion using UV-visible spectroscopy. We also investigated the effects of reaction conditions such as temperature, $\mathrm{pH}$, quantities of bark extract and $\mathrm{AgNO}_{3}$ concentration on the synthesis rate. The silver nanoparticles were further characterized by X-ray diffraction (XRD), scanning electron microscopy (SEM), energy dispersive $\mathrm{X}$-ray (EDX) spectrometer, and Fourier transform infrared spectroscopy (FTIR). Furthermore, the antibacterial activity of the silver nanoparticles on a strain of Escherichia coli and Staphylococcus aureus was qualitatively evaluated by the zone inhibition method.

\section{Materials and methods}

\section{Preparation of Afzelia quanzensis bark powder and extract}

The bark was obtained from Afzelia quanzensis tree in Chivi rural district area, Zimbabwe. The bark was washed to remove any impurities and dried under sunlight for a week to completely remove the moisture. The bark was cut into small pieces, powdered in a mixer and then sieved using a 20-mesh sieve to get uniform size range. The sieved powder was used for all further studies. For the production of an extract, $50 \mathrm{~g}$ of powdered bark was added to a 500-mL Erlenmeyer flask containing $200 \mathrm{~mL}$ deionized water and then boiled for $15 \mathrm{~min}$. After cooling, the mixture was filtered through Whatman filter paper no. 1 and the extract was kept at $4{ }^{\circ} \mathrm{C}$ prior to silver nanoparticles synthesis.
Fig. 1 Mechanism involved in the synthesis of silver nanoparticles using Afzelia quanzensis extract

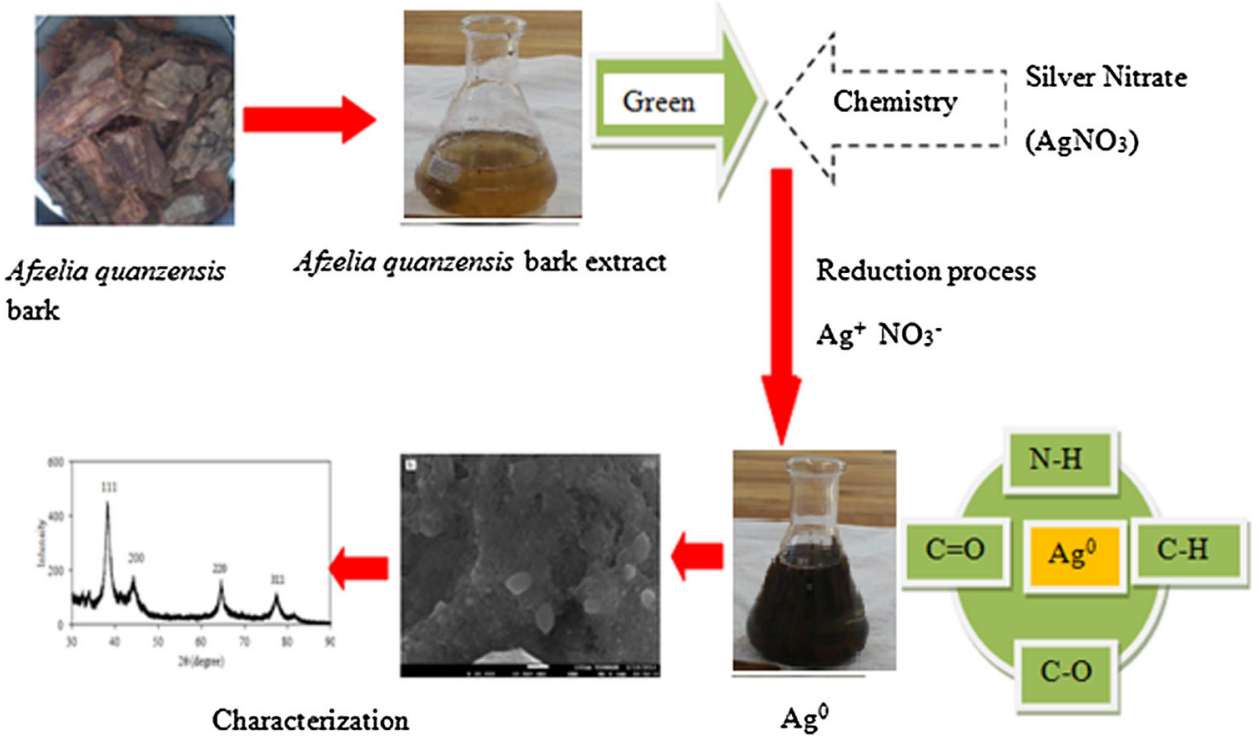




\section{Synthesis of silver nanoparticles}

Silver nitrate $\left(\mathrm{AgNO}_{3}\right)$ analytical grade used as a precursor was purchased from Sigma-Aldrich (Pretoria, South Africa). For the AgNPs synthesis, $5 \mathrm{~mL}$ bark extract were added to $50 \mathrm{~mL}$ of $1 \mathrm{mM}$ aqueous $\mathrm{AgNO}_{3}$ solution in a 250-mL Erlenmeyer flask. The flask was then incubated in a rotary shaker at $160 \mathrm{rpm}$ in the dark. The reduction of silver ions was routinely monitored visually for colour change at regular intervals. Thereafter, the silver nanoparticle solution thus obtained was purified by repeated centrifugation at $500 \mathrm{rpm}$ for $20 \mathrm{~min}$ followed by redispersion of the pellet of silver nanoparticles into a $10 \mathrm{~mL}$ of deionized water. After freeze drying, lyophilization process was performed on the purified silver nanoparticles to obtain the powdered form which was stored in brown bottles prior to physical characterization and antibacterial activity.

\section{Characterization}

\section{UV-Vis spectrophotometer analysis}

The preliminary reduction of synthesized silver nanoparticles was monitored using UV-visible spectrophotometer (Shimadzu UV-1601, Japan) by scanning the absorbance spectra in the range of $300-600 \mathrm{~nm}$. All sample solutions were diluted using a ratio of 1:10.

\section{Electron microscopic study}

SEM analysis of the synthesized silver nanoparticles was done using a Hitachi S-4500 SEM machine (Japan). A thin layer of gold was used to coat the samples through vacuum evaporation so that the nanoparticles conducts evenly and provides a homogeneous surface for analysis and imaging on an aluminium slab. The elemental analysis was performed using EDX (JEOL-JSM-5800LV, Tokyo, Japan) which is an attachment to the SEM. The sample powder of AgNPs was compressed to form tablets before analysis with EDX spectrum.

\section{$X R D$ analysis}

The dried synthesized silver nanoparticles were analysed using an X-ray diffractometer (D8 Bruker, Germany) with $\mathrm{Cu} K_{\alpha}$ radiation in the range of $30^{\circ} \leq 2 \theta \leq 90^{\circ}$ at $40 \mathrm{kV}$ and $40 \mathrm{~mA}$.

\section{FTIR analysis}

FTIR (PerkinElmer, US) spectra were obtained at room temperature in the spectral range between 480 and
$4000 \mathrm{~cm}^{-1}$. FTIR measurements were made to identify the possible biomolecules responsible for capping and efficient stabilization of the synthesized silver nanoparticles.

\section{Study for the influence of different parameters}

Influence of different temperatures $(30,40,50,60,70,80$, $\left.90{ }^{\circ} \mathrm{C}\right)$, $\mathrm{pH}$ values $(3,5,7,8,11)$, bark extract amounts $(2$, $4,6,8,10,12,14 \mathrm{~mL})$, substrate concentrations $(1,3,5,7$, 9, $11,13 \mathrm{mM} \mathrm{AgNO}$ ) and incubation periods (20, 40, 60, $80,100,120,140 \mathrm{~min}$ ) were investigated by varying the parameters one at a time. A sample of $1 \mathrm{~mL}$ was withdrawn at different time intervals and the absorbance was measured at $427 \mathrm{~nm}$.

\section{Measuring concentration of AgNPs using inductively coupled plasma optical emission spectrophotometer (ICP-OES)}

The original concentration $(80 \mathrm{mg} / \mathrm{L})$ of the Afzelia quanzensis bark extract mediated AgNPs was measured using ICP-OES. Then, by diluting this solution, samples of different concentrations $(10,25,50 \mathrm{mg} / \mathrm{L})$ were used to investigate the concentration dependence of the antibacterial effect of Ag nanoparticles.

\section{Evaluation of antibacterial activity of synthesized silver nanoparticles}

The synthesized silver nanoparticles were tested for their antibacterial activity by using the disk diffusion method. The cultures of Staphylococcus aureus (ATCC-25923) and Escherichia coli (ATCC-39403) were obtained from American Type Culture Collection Center, USA. S. aureus and E. coli were grown on Mueller-Hinton agar medium. The disk diffusion was performed by placing different types of disks including bark extract $(50 \mu \mathrm{L})$, synthesized silver nanoparticles $(50 \mu \mathrm{L} / 10,25,50 \mathrm{mg} / \mathrm{L})$, standard antibiotic (erythromycin $50 \mu \mathrm{L}$ ) and synthesized silver nanoparticles with standard antibiotic on the surface of the agar in plates and incubated for $24 \mathrm{~h}$ at $37{ }^{\circ} \mathrm{C}$. The zones of inhibition were measured by the Hi-Media scale.

\section{Results and discussion}

\section{Visual analysis}

Afzelia quanzensis bark extract when incubated with $\mathrm{AgNO}_{3}$ solution under dark conditions changed its colour from colourless to light reddish and finally to reddish brown. The colour of the filtrate changed to intense brown after $120 \mathrm{~min}$ of incubation (Fig. 2b, c). The control 
Fig. 2 Optical photograph of $1 \mathrm{mM} \mathrm{AgNO}$ solution (a) filtrate with silver ions at the beginning of reaction (b) and after $120 \mathrm{~min}$ of reaction (c)
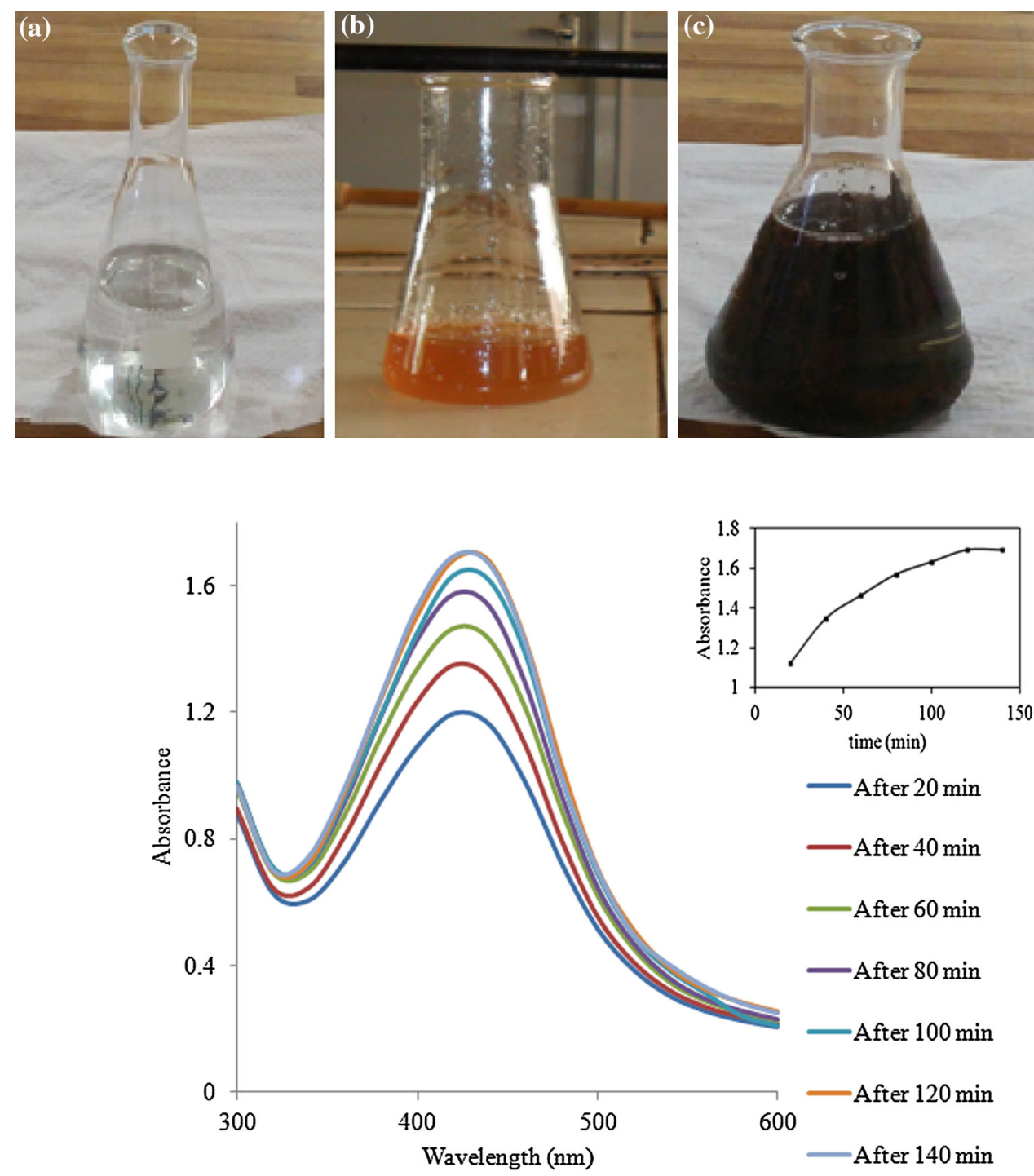

Fig. 3 The UV-visible absorption spectra of synthesized AgNPs. The inset shows the change in SPR as a function of time
$\mathrm{AgNO}_{3}$ solution (without Afzelia quanzensis bark extract) showed no change in colour (Fig. 2a). The possible chemical reactions involved in the preparation of the AgNPs can be represented as:

$$
\begin{aligned}
& \mathrm{Ag}_{(\mathrm{aq})}^{+}+\text {Afzelia quanzensis } \frac{\text { Stirring at room temperature }}{\left[\text { Stirring for } 120 \text { min at } 70^{\circ} \mathrm{C}\right]} \\
& \quad[\mathrm{Ag}(\text { Afzelia quanzensis })]^{+} \\
& \quad[\mathrm{Ag}(\text { Afzelia quanzensis })]^{+}+\mathrm{R}-\mathrm{CHO} \\
& \quad \rightarrow[\mathrm{Ag}(\text { Afzelia quanzensis })]+\mathrm{R}-\mathrm{COOH}
\end{aligned}
$$

\section{UV-Vis spectra analysis}

The development of metal silver nanoparticles in aqueous solution was described by UV-Vis spectroscopy. The absorption spectra of AgNPs formed at different durations are shown in (Fig. 3).
From Fig. 3, it can be observed that the plasmon band was symmetric, indicating that the solution does not have much aggregated particles [27]. The evolution of an absorption spectra for the AgNPs shows an increasingly sharp absorbance at $427 \mathrm{~nm}$ with increase in time, which steadily increased in intensity as a function of reaction time without showing any shift of the maximum wavelength [2]. This phenomenon may be linked to polarization of the free conduction electrons with respect to the much heavier ionic core of AgNPs, resulting in electron dipolar oscillation after exposure of AgNPs to light [12]. For quality assurance and comparison, $\mathrm{AgNO}_{3}$ solution in deionized water showed no absorption peak at the same wavelength range (data not shown). In the present bark extract/Ag investigation, the reaction mixtures showed a single SPR band revealing the spherical shape of AgNPs which is in good agreement to the Mie's theory [28]. Consequently, this 


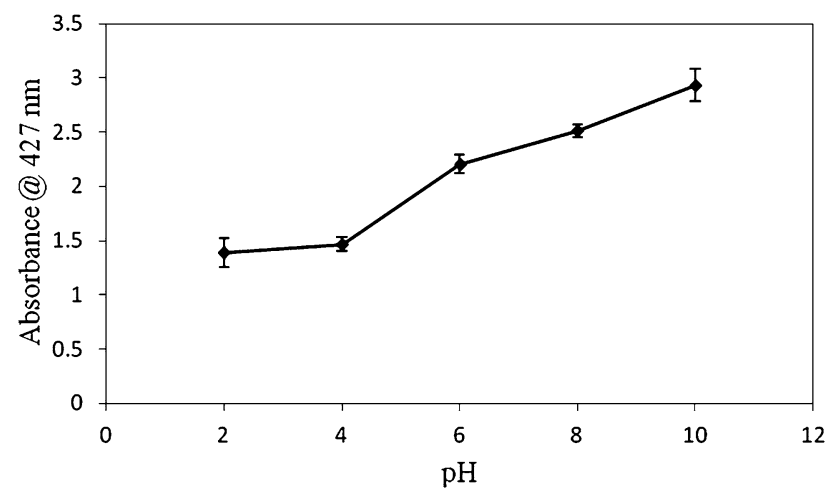

Fig. 4 Effect of different $\mathrm{pH}$ on nanoparticle production (error bar $\pm \mathrm{SD}$ and $n=3$ )

validates the application of Afzelia quanzensis bark extract as a precursor for AgNPs synthesis.

\section{Study for the influence of different parameters}

The biosynthesis of AgNPs is affected by a variety of factors (substrate concentration, electron donor, incubation time, $\mathrm{pH}$, temperature, buffer strength, etc.) which control the shape and size as well as achieving the monodispersity in solution phase. In this study, the effects of $\mathrm{pH}, \mathrm{AgNO}_{3}$ concentrations, different quantities of bark extract, and different temperatures were investigated.

\section{Effect of $p H$}

The size and morphology of nanoparticles are mainly affected by the $\mathrm{pH}$ of solution [29-31]. As shown by UVVis spectroscopy (Fig. 4), when the $\mathrm{pH}$ of the reaction mixture was increased, an increase in absorbance was observed. This might be due to the increase in production of colloidal silver nanoparticles and reduction rate. Visual observation showed the amount of nanoparticles to be $\mathrm{pH}$ value dependent. The reaction mixture colouring accelerated when the $\mathrm{pH}$ was increased. At acidic $\mathrm{pH}$, large-sized silver nanoparticles were observed, whilst at higher $\mathrm{pH}$ highly dispersed, small-sized nanoparticles were formed. The results are in agreement with those reported in literature [32-34]. Control experiments $\left(\mathrm{AgNO}_{3}\right.$ solution incubated at different alkaline $\mathrm{pH} 8,9,10$ ) showed no synthesis of nanoparticles.

\section{Effect of $\mathrm{AgNO}_{3}$ concentration}

The concentration of $\mathrm{AgNO}_{3}$ which might be converted to a final product is one of the important measures required to make the reaction more economical and efficient [31]. The effect of $\mathrm{AgNO}_{3}$ concentration on synthesis of $\mathrm{AgNPs}$ is shown in Fig. 5.

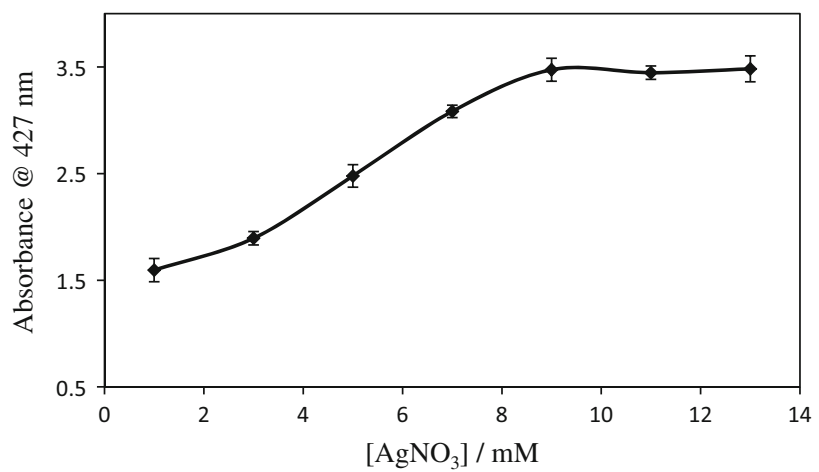

Fig. 5 Effect of $\mathrm{AgNO}_{3}$ concentration (error bar $\pm \mathrm{SD}$ and $n=3$ )

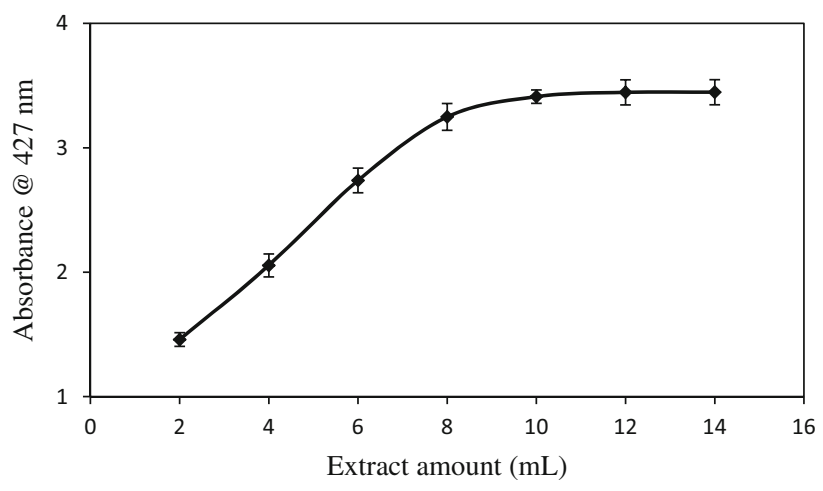

Fig. 6 Effect of different quantities of Afzelia quanzensis bark extract (error bar \pm SD and $n=3$ )

There was an increase in synthesis of AgNPs with respect to $\mathrm{Ag}^{+}$ion concentration in the range $1-9 \mathrm{mM}$. However, the absorbance was found to decrease at concentrations greater than $9 \mathrm{mM}$. Comparable results were obtained for the synthesis AgNPs using Pinus eldarica bark extract [31]. Consequently, $9 \mathrm{mM}$ was used for further studies.

\section{Effect of different quantities of Afzelia quanzensis bark extract}

The production of AgNPs was monitored as a function of different amounts of Afzelia quanzensis bark extract amount. Figure 6 shows the effect of extract amount on AgNPs production. The increase in the extract amount from 2 to $10 \mathrm{~mL}$ caused a considerable increase in peak absorbance in UV-Vis spectrum. The increase in the amount of soluble phytochemical reducing agents in the extract would mean more $\mathrm{Ag}^{+}$ion reduction, and subsequently more nanoparticle production. Furthermore, a decrease in amount of Ag nanoparticles was observed due to an increase in extract amount above $10 \mathrm{~mL}$. 


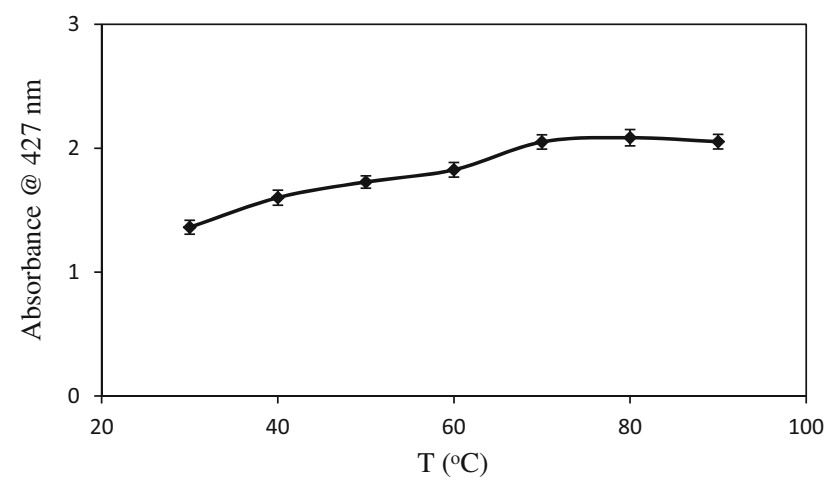

Fig. 7 Effect of reaction temperature (error bar $\pm \mathrm{SD}$; and $n=3$ )

\section{Effect of temperature}

The role of temperature on the reaction rate from 30 to $70{ }^{\circ} \mathrm{C}$ was investigated. An increase in absorbance was noted as the temperature increased (Fig. 7). The enhanced rate of synthesis of AgNPs might be due to the reaction temperature increasing the kinetic energy of the reacting molecules thus more $\mathrm{Ag}^{+}$ions were in collision with the reducing molecules of the extract. The maximal synthesis of AgNPs was achieved at $70{ }^{\circ} \mathrm{C}$.

\section{Characterization}

\section{Electron microscopic study}

The SEM images of the $\mathrm{AgNO}_{3}$ (Fig. 8a) and synthesized silver nanoparticles (Fig. 8b) were clearly noticeable. The size of the silver nitrate particles used as control in this study was greater than $1000 \mathrm{~nm}$ size (Fig. 8a); whereas, the synthesized silver nanoparticles measured $10-80 \mathrm{~nm}$ in size (Fig. 8b). Similar to our study, the same pattern of silver nanoparticles were also reported [24]. The EDAX spectroscopy results confirmed the significant presence of $61.66 \%$ silver, $30.47 \%$ carbon and oxygen $7.87 \%$ (Fig. 9). Metallic silver nanocrystals generally show a typical optical absorption peak approximately at $3 \mathrm{keV}$ due to surface plasmon resonance [35]. The weak signals at 0.25 and $0.50 \mathrm{keV}$ were are for carbon and oxygen, respectively, which might arise from the functional compounds present in the aqueous extract.

\section{XRD: purity and crystalline nature of AgNPs}

The phase of the vacuum dried nanoparticles was investigated by XRD and corresponding patterns are shown in Fig. 10. However, silver nanoparticles have shown clear peaks of cubic phases (JCPDS No. 03-0921) at 38.1 (111), 42.9 (200), 65.5 (220) and 77.9 (311). XRD pattern thus
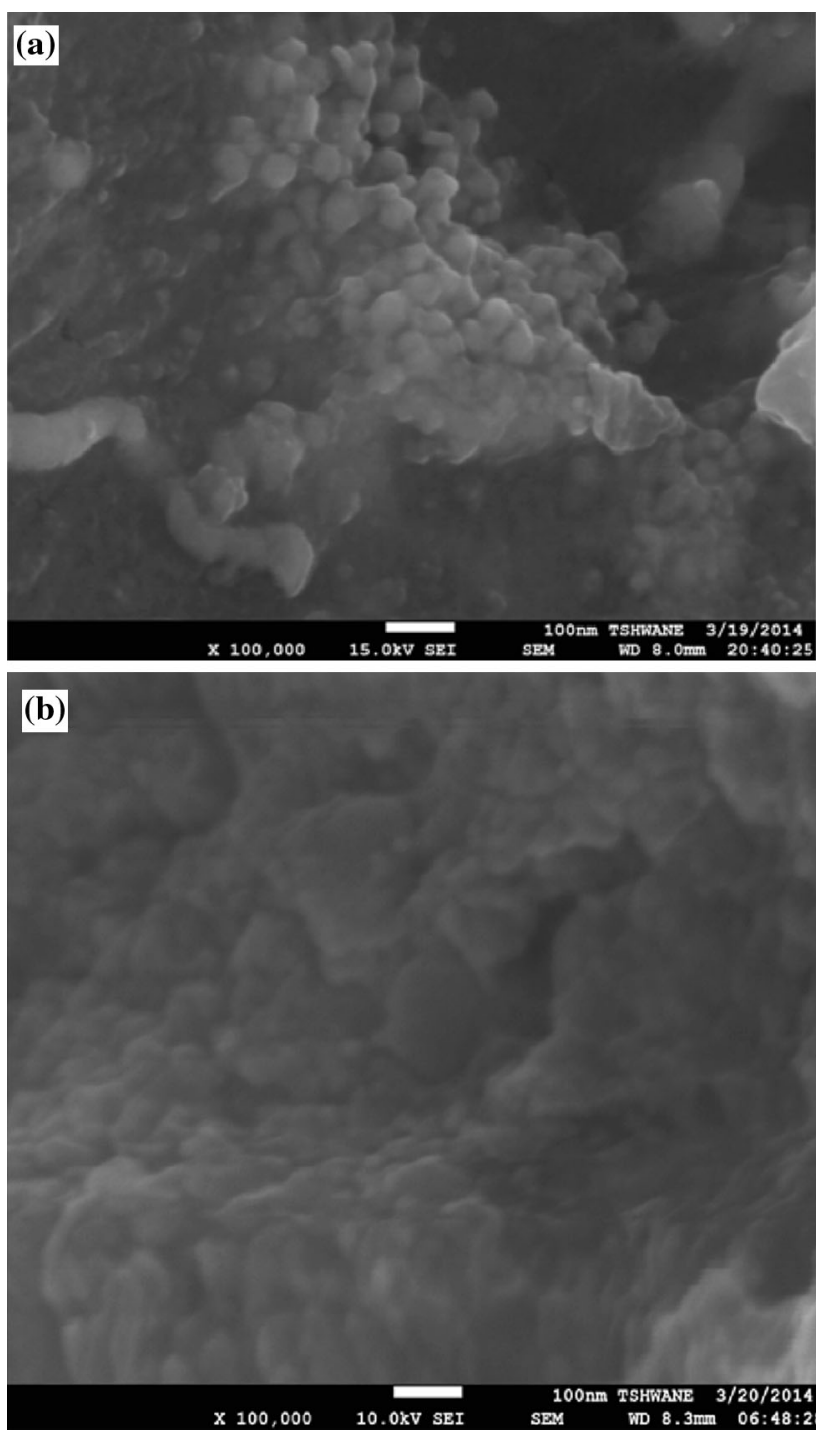

Fig. 8 Scanning electron microscopic observation of a silver nitrate and $\mathbf{b}$ synthesized

clearly illustrates that the silver nanoparticles formed in this present synthesis are crystalline in nature. There were no other corresponding peaks observed from the XRD pattern which showed that the formed AgNPs have a high purity. Previous studies have also reported the crystalline nature of biosynthesized AgNPs using different plant extracts $[3,9,22,23,36]$. The average crystalline size of silver nanoparticles synthesized using Afzelia quanzensis bark extract can be calculated using the Scherrer equation [25]:

$D=\frac{K \lambda}{\beta \operatorname{Cos} \theta}$,

where $D$ is the crystallite size of AgNPs, $\lambda$ is the wavelength of the $\mathrm{X}$-ray source $(0.1541 \mathrm{~nm}), \beta$ is the full width at half maximum of the diffraction peak, $K$ is the Scherrer 


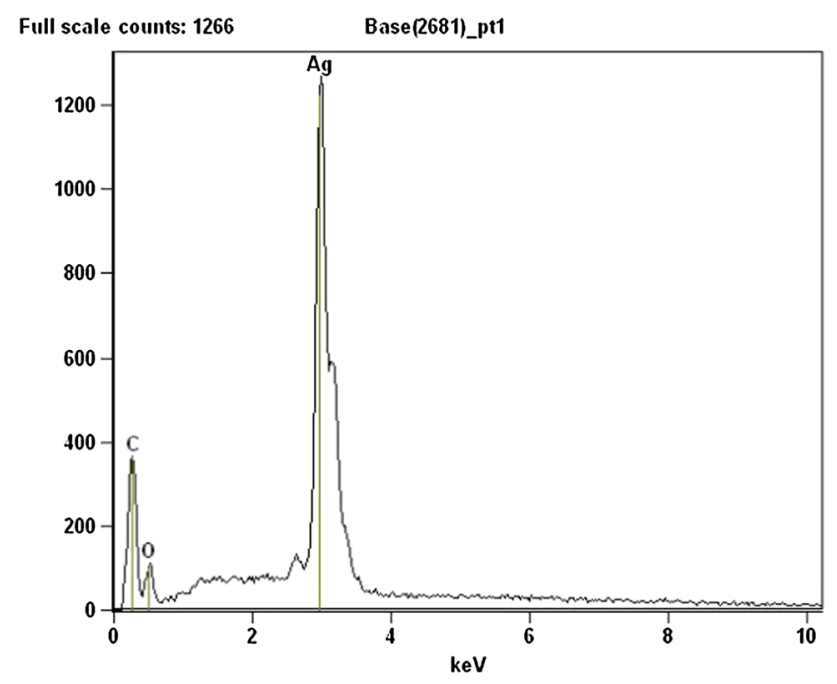

Fig. 9 The EDX spectrum for AgNPs

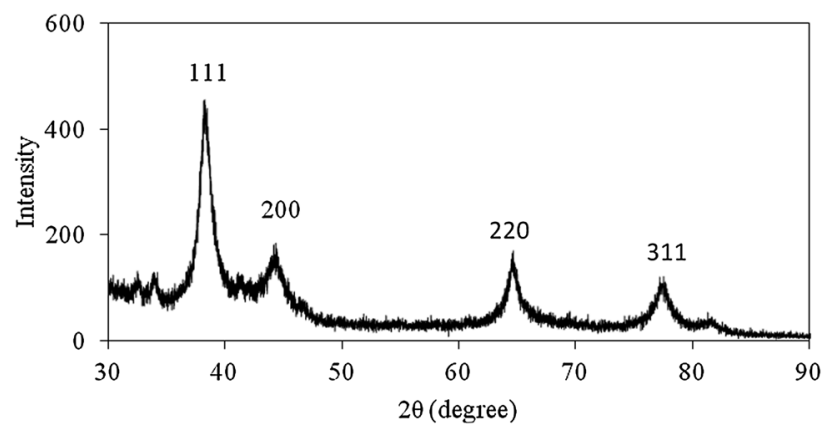

Fig. 10 XRD spectra of AgNPs

constant with a value from 0.9 to 1 , and $\theta$ is the Bragg angle. The average crystalline size was $19.8 \mathrm{~nm}$. The obtained average crystalline size coupled with the presence of structural peaks in XRD patterns clearly illustrated that the AgNPs synthesized were nanocrystalline in nature.

\section{FTIR analysis}

The FTIR spectra of Afzelia quanzensis extract and synthesized AgNPs were examined (Fig. 11). The strong band at $3455 \mathrm{~cm}^{-1}$ on the Afzelia quanzensis extract is characteristic of $\mathrm{N}-\mathrm{H}$ and $\mathrm{O}-\mathrm{H}$ stretching vibrations [35]. The characteristic absorption band at $2933 \mathrm{~cm}^{-1}$ is due to alkyl chains. The FTIR spectra also show bands at 1637 and $1445 \mathrm{~cm}^{-1}$ identified as amide I and amide II which arise due to carbonyl $(\mathrm{C}=\mathrm{O})$ and amine $(-\mathrm{NH})$ stretching vibrations in the amide linkages of the proteins, respectively. The peaks at 1264 and $1060 \mathrm{~cm}^{-1}$ may be due to a carboxylate group $\left(\mathrm{COO}^{-}\right)$and phosphate group, respectively. After reduction of $\mathrm{AgNO}_{3}$, the band characteristic of $\mathrm{N}-\mathrm{H}$ and $\mathrm{O}-\mathrm{H}$ stretching vibrations shifted to $3424 \mathrm{~cm}^{-1}$

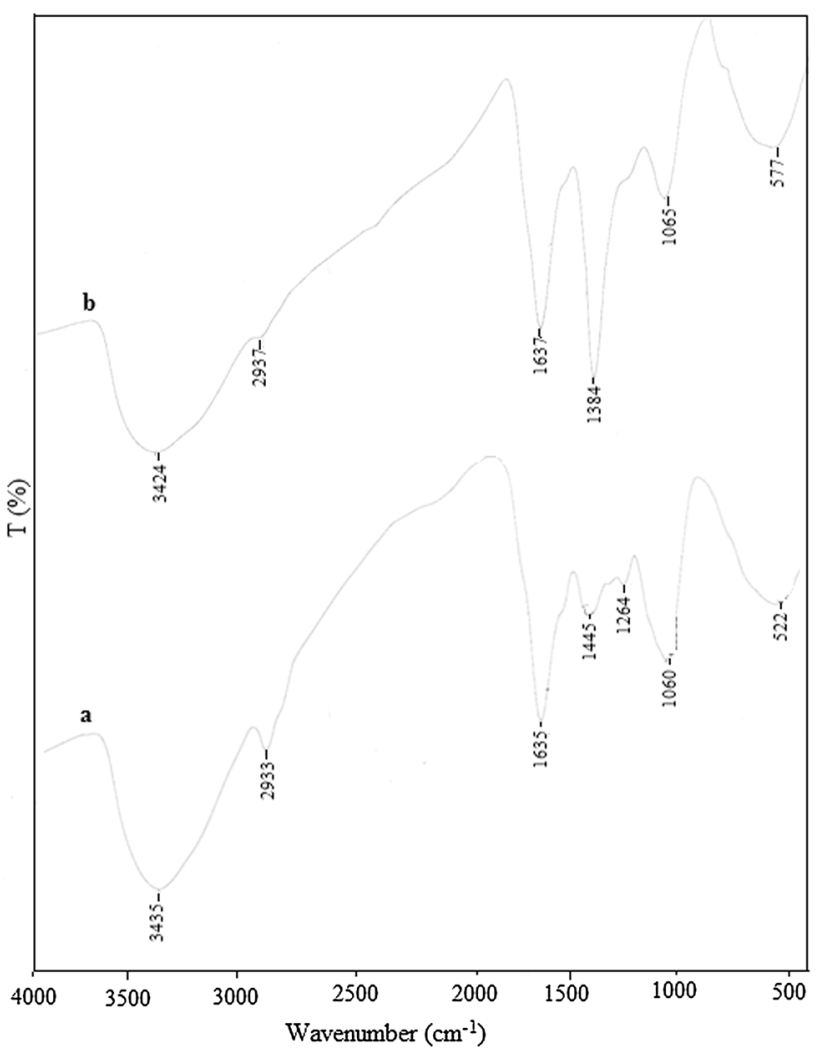

Fig. 11 FTIR spectra of Afzelia quanzensis extract (a) and synthesized AgNPs (b)

and alkyl group decreased in intensity, and shifted to $2937 \mathrm{~cm}^{-1}$. The disappearance of the peaks at 1445 and $1264 \mathrm{~cm}^{-1}$ and formation of new intense peak at $1384 \mathrm{~cm}^{-1}$, signify the involvement of the secondary amines in the reduction process. The shift of the band from 1635 to $1637 \mathrm{~cm}^{-1}$ is attributed to the binding of $(\mathrm{NH}) \mathrm{CO}$ group with nanoparticles. It can be concluded from the FTIR study that the carboxyl $(-\mathrm{C}=\mathrm{O})$ and amine $(\mathrm{N}-\mathrm{H})$ groups in Afzelia quanzensis bark extract were mainly involved in reduction of $\mathrm{Ag}^{+}$ions to $\mathrm{Ag}^{0}$ nanoparticles.

\section{Stability studies}

A vital aspect in colloid chemistry is how nano-scale particles are stabilized in their reaction media as smaller particles are prone to agglomeration. The stability of the AgNPs in solution was checked using UV-Vis spectroscopy by observing changes in the SPR band peak [37]. Figure 12 shows UV-Vis spectra periodically obtained over 60 days. The AgNPs produced from bark extract were observed to be very stable in solution when monitored periodically over a period of 40 days; with no evidence of flocculation or change in SPR, measured at $427 \mathrm{~nm}$. However, after 50 days the surface plasmon resonance absorption band decreased and can be attributed to 
Fig. 12 Stability studies

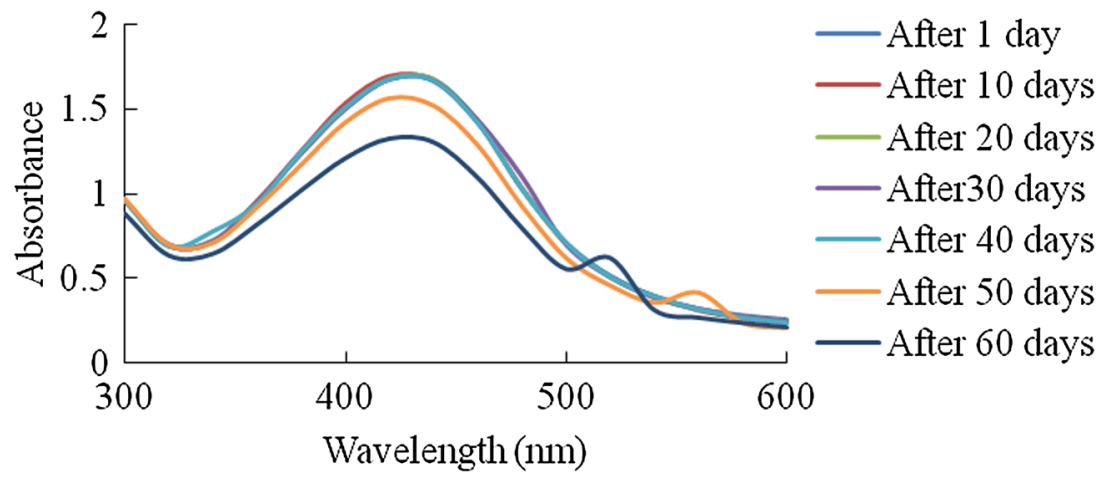

Fig. 13 Graphical representation of inhibition zones by plant extract $(a)$, $10 \mathrm{mg} / \mathrm{L}$ synthesized AgNPs (b), $25 \mathrm{mg} / \mathrm{L}$ synthesized AgNPs $(c), 50 \mathrm{mg} / \mathrm{L}$ synthesized AgNPs $(d)$, erythromycin $(e)$, erythromycin plus $10 \mathrm{mg} / \mathrm{L}$ synthesized AgNPs $(f)$, erythromycin plus $25 \mathrm{mg} / \mathrm{L}$ synthesized AgNPs $(g)$, erythromycin plus $50 \mathrm{mg} / \mathrm{L}$ synthesized AgNPs $(h)$, for a Escherichia coli, b Staphylococcus aureus (error bar $\pm \mathrm{SD}$ and $n=3$ )

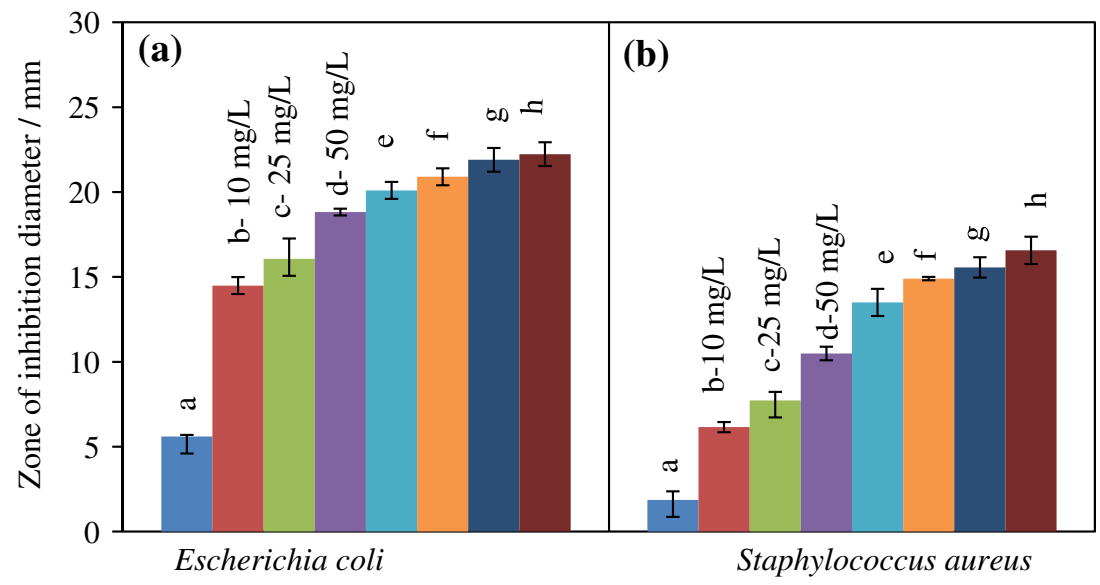

Name of organism

destabilization of AgNPs in solution due to aggregation. Between 50 and 60 days secondary peaks appear at longer wavelength which is a sign of destabilization.

\section{Evaluation of antibacterial activity of synthesized silver nanoparticles}

The antimicrobial activity of bark extract (a), synthesized AgNPs of different concentrations (b-d), the antibiotic (erythromycin) (e) and antibiotic plus different concentrations of synthesized AgNPs (f-h) were evaluated by diffusion method. The bacterial cultures used were Grampositive bacteria, i.e. Staphylococcus aureus and Gramnegative bacteria, i.e. Escherichia coli. The increase in zone of inhibition of silver nanoparticles at different concentrations $(10,25,50 \mathrm{mg} / \mathrm{L})$ compared with antibiotic for both bacterial cultures (Fig. 13a, b) demonstrated the lesser antibacterial potential of silver nanoparticles with that of antibiotics. The zone of inhibition also increased with AgNPs concentration in both cultures. The bark extract exhibits the highest activity against $E$. coli than $S$. aureus. The obtained results support, at least in part, the use of this plant as traditional medicine against Gram-negative bacteria due to the presence of phytochemicals. Furthermore, the phytofabricated silver nanoparticles were found to be more effective against Escherichia coli as compared to that of Staphylococcus aureus. From Fig. 13a, b, it can be confirmed that combining the antibiotics with AgNPs resulted in a greater bactericidal effect on test pathogens than either of the antibacterial agents used alone. Inhibition of Escherichia coli might have been facilitated by silver's high affinity for phosphorus and sulphur which are part of the cell membranes of Gram-negative bacteria [38]. The sulphur and phosphorus reacts with AgNPs causing dysfunction of enzymes on bacteria cell wall and also it disturbs DNA's moieties process thereby denying replication [39]. On the other hand, the cell wall of Gram-positive bacteria is much more rigid due to the presence of a thick peptidoglycan layer, which is superficial to the cell membrane hence a difference in activity observed.

\section{Conclusion}

The silver nanoparticles were green synthesized using bark extract of Afzelia quanzensis. The method represents an example of clean, nontoxic and eco-friendly method for obtaining silver nanoparticles. Colour changes occur due to 
surface plasmon resonance during the reaction with Afzelia quanzensis bark extract resulting in the formation of silver nanoparticles, which was confirmed by XRD, FTIR, UVVis spectroscopy, and EDAX. The silver nanoparticles were found to be stable in water for 40 days. The zone of inhibition test showed that the synthesized nanoparticles have some antibacterial activity. Further studies will be conducted to isolate and quantify the different phytochemical components and to study their pharmacological properties after synthesizing the silver nanoparticles from the specific phytochemicals.

\section{Compliance with ethical standards}

Conflict of interest The authors have no conflict of interest.

Open Access This article is distributed under the terms of the Creative Commons Attribution 4.0 International License (http://crea tivecommons.org/licenses/by/4.0/), which permits unrestricted use, distribution, and reproduction in any medium, provided you give appropriate credit to the original author(s) and the source, provide a link to the Creative Commons license, and indicate if changes were made.

\section{References}

1. Kathiresan K, Manivannan S, Nabeel MA, Dhivya B (2009) Studies on silver nanoparticles synthesized by a marine fungus, Penicillium fellutanum isolated from coastal mangrove sediment. Colloids Surf 71:133-137

2. Sridhara V, Pratima K, Krishnamurthy G, Sreekanth B (2013) Vegetable assisted synthesis of silver nanoparticles and its antibacterial activity against two human pathogens. Asian J Pharm Clin Res 6:53-57

3. Awwad AM, Salem NM, Abdeen AO (2013) Green synthesis of silver nanoparticles using carob leaf extract and its antibacterial activity. Intern J Indust Chem 4:29-35

4. Peterson MSM, Bouwman J, Chen Deutsch AM (2007) Inorganic metallodielectric materials fabricated using two single-step methods based on the Tollen's process. J Colloid Interface Sci 306:41-49

5. Shao K, Yao J (2006) Preparation of silver nanoparticles via a non-template method. Mater Lett 60:3826-3829

6. Tsuji T, Iryo K, Watanabe N, Tsuji M (2002) Preparation of silver nanoparticles by laser ablation in solution: influence of laser wavelength on particle size. Appl Surf Sci 202:80-85

7. Nagaraz B, Krishnamurthy NB, Liny P, Divya TK, Dinesh R (2011) Biosynthesis of gold nanoparticles of Ixora coccinea flower extract and their antimicrobial activities. Int J Pharma Bio Sci 2:557-565

8. Bar H, Bhui DK, Sahoo GP Sarkar P, De SP, Misra A (2009) Green synthesis of silver nanoparticles using latex of Jatropha curcas. Colloids Surf 339:134-139

9. Bar H, Bhui DK, Sahoo GP, Sarkar P, Pyne S, Misra A (2009) Green synthesis of silver nanoparticles using seed extract of $\mathrm{Ja}$ tropha curcas. Colloids Surf A 348:212-216

10. Das VL, Thomas R, Varghese RT, Soniya EV, Mathew J, Radhakrishnan EK (2014) Extracellular synthesis of silver nanoparticles by the Bacillus strain CS 11 isolated from industrialized area3. Biotech 4(2):121-126
11. Ghorbani HR (2013) Biosynthesis of silver nanoparticles using Salmonella typhirium. J Nanostruct Chem 3(29):1-4

12. Swarup R, Kumar DT (2014) Biosynthesis of silver nanoparticles by Aspergillus foetidus: optimization of physicochemical parameters. Nanosci Nanotechnol Lett 6(3):181

13. Prasad K, Anal KJ, Kulkarni AR (2007) Lactobacillus assisted synthesis of titanium nanoparticles. Nanoscale Res Lett 2:248-250

14. Jha AK, Kamalesh P, Prasad K (2009) A green low-cost biosynthesis of $\mathrm{Sb}_{2} \mathrm{O}_{3}$ nanoparticles. Biochem Eng J 43:303-306

15. Hebbalalu D, Lalley J, Nadagouda MN, Varma RS (2013) Greener techniques for the synthesis of silver nanoparticles using plant extracts, enzymes, bacteria, biodegradable polymers, and microwaves. ACS Sustain Chem Eng 1(7):703-712

16. Prathap M, Alagesan A, Ranjitha Kumari BD (2014) Anti-bacterial activities of silver nanoparticles synthesized from plant leaf extract of Abutilon indicum (L.) Sweet. J Nanostruct Chem 4:106

17. Lee SH, Salunke BK, Kim BS (2014) Sucrose density gradient centrifugation separation of gold and silver nanoparticles synthesized using Magnolia kobus plant leaf extracts. Biotechnol Bioprocess Eng 19:169-174

18. Murugan K, Senthilkumar B, Senbagam D, Al-Sohaibani S (2014) Biosynthesis of silver nanoparticles using Acacia leucophloea extract and their antibacterial activity. Int $\mathrm{J}$ Nanomed 9:2431-2438

19. Maria BS, Devadiga A, Kodialbail VS, Saidutta MB (2015) Synthesis of silver nanoparticles using medicinal Zizyphus xylopyrus bark extract. Appl Nanosci 5:755-762

20. Chandran SP, Chaudhary M, Pasricha R, Ahmad A, Sastry M (2006) Synthesis of gold nanotriangles and silver nanoparticles using aloevera plant extract. Biotechnol Progress 22:577-583

21. Sharma NC, Sahi SV, Nath S, Parsons JG, Gardea-Torresdey JL, $\mathrm{Pal} T$ (2007) Synthesis of plant-mediated gold nanoparticles and catalytic role of biomatrix embedded nanomaterials. Environ Sci Technol 41:5137-5142

22. Sathishkumar M, Sneha K, Won SW, Cho CW, Kim S, Yun YS (2009) Cinnamon zeylanicum bark extract and powder mediated green synthesis of nano-crystalline silver particles and its bactericidal activity. Colloids Surf B 73:332-338

23. Sathishkumar M, Sneha K, Yun YS (2010) Immobilization of silver nanoparticles synthesized using curcuma longa tuber powder and extract on cotton cloth for bactericidal activity. Bioresour Technol 101:7958-7965

24. Bhati-Kushwaha H, Malik CP (2014) Biosynthesis of silver nanoparticles using fresh extracts of Tridax procumbens Linn. Indian J Exp Biol 52:359-368

25. Ahmad N, Sharma S, Alam MK, Singh VN, Shamsi SF, Mehta BR, Fatma A (2010) Rapid synthesis of silver nanoparticles using dried medicinal plant of basil. Colloids Surf B 81:81-86

26. Biegel HM (1977) Check-list of ornamental plants used in Rhodesian parks and gardens. Rhod Agric J Res Rep 3:19-20

27. Link S, El-Sayed MA (1999) Spectral properties and relaxation dynamics of surface plasmon electronic oscillations in gold and silver nanodots and nanorods. J Phys Chem B 103:8410-8426

28. Ghadimi A, Saidur R, Metselaar HSC (2011) A review of nanofluid stability properties and characterization in stationary conditions. Int J Heat Mass Transf 54:4051-4068

29. Konishi Y, Tsukiyama TTT, Saitoh N, Nomura T, Nagamine S (2007) Microbial deposition of gold nanoparticles by the metal-reducing bacterium Shewanella algae. Electrochim Acta 53:186-192

30. Sanghi R, Verma P (2009) Biomimetic synthesis and characterisation of protein capped silver nanoparticles. Bioresour Technol 100:501-504

31. Iravani S, Zolfaghari B (2013) Green synthesis of silver nanoparticles using pinus bark extract. Biomed Res Int 2013:1-5 
32. Gardea-Torresdey JL, Tiemann KJ, Gamez G, Dokken K, Tehuacanero S, Jośe-Yacaman M (1999) Gold nanoparticles obtained by bio-precipitation from gold (III) solutions. J Nanopart Res 1:397-404

33. Birla SS, Gaikwad SC, Gade AK, Rai MK (2013) Rapid synthesis of silver nanoparticles from fusarium oxysporum by optimizing physicocultural conditions. Sci World J 2013:1-12. doi:10.1155/ 2013/796018

34. Armendariz V, Herrera I, Peralta-Videa JR (2004) Size controlled gold nanoparticle formation by Avena sativa biomass: use of plants in nanobiotechnology. J Nanopart Res 6:377-382

35. Das SK, Khan MMR, Guha AK, Das AR, Mandal AB (2012) Silver-nano biohybride material: synthesis, characterization and application in water purification. Bioresour Technol 124:495-499

36. Krishnaraj C, Jagan EG, Rajasekar S, Selvakumar P, Kalaichelvan PT, Mohan N (2010) Synthesis of silver nanoparticles using
Acalypha indica leaf extracts and its antibacterial activity against water borne pathogens. Colloids Surf B 76:50-56

37. Lee DK, Tho NTM, Minhan TN, Tri MD, Sreekanth TVM, Lee JS, Nagajyothi PC (2013) Green synthesis of silver nanoparticles using Nelumbo nucifera seed extract and its antimicrobial activity. Acta Chim Slov 60:673-678

38. Hari N, Thomas TK, Nair AJ (2014) Comparative study on the synergistic action of differentially synthesized silver nanoparticles with $\beta$-Cephem antibiotics and chloramphenicol. J Nanosci 2014:1-8

39. Shetty P, Supraja N, Garud M, Prasad TNVKV (2014) Synthesis, characterization and antimicrobial activity of Alstonia scholaris bark-extract-mediated silver nanoparticles. J Nanostruct Chem 4(4):161-170 